\title{
TIOB9 monoclonal antibody: A short-acting nonstimulating monoclonal antibody that spares $\gamma \delta$ T-cells and treats and prevents cellular rejection
}

This article was published in the following Dove Press journal:

Drug Design, Development and Therapy

23 June 2009

Number of times this article has been viewed

\author{
Thomas H Waid' \\ John S Thompson' \\ Maria Siemionow ${ }^{2}$ \\ Stephen A Brown' \\ 'Department of Internal Medicine, \\ University of Kentucky, Lexington, \\ Kentucky, USA; ${ }^{2}$ Cleveland Clinic, \\ Cleveland, Ohio, USA
}

Correspondence:Thomas HWaid Professor of Internal Medicine, Medical Director, Heart-Lung, Kidney and Pancreas Transplantation University of Kentucky, Lexington, Kentucky, USA Email thomas.waid@uky.edu

\begin{abstract}
T10B9.1A-31/MEDI-500 is a nonmitogenic immunoglobulin M kappa murine monoclonal antibody $(\mathrm{mAb})$ directed against the alpha-beta $(\alpha \beta)$ heterodimer of the T-lymphocyte receptor complex. The hybridoma was first produced by fusing spleen cells from BALB/C mice immunized with human peripheral blood T-lymphocytes with SP2/O-Ag14 mutant myeloma cells. The mAb is produced and purified using multistep ion exchange and molecular sieve chromatography protocols. T10B9 has been used successfully to treat acute cellular rejection in renal transplantation and as an immunosuppression induction agent in heart and simultaneous kidney-pancreas transplantation. Because T10B9 is nonmitogenic and causes minimal cytokine release, both treatment of rejection and induction of immunosuppression were accomplished with significantly fewer and milder untoward effects (cytokine release syndrome) than its comparator OKT3. Since T10B9 is directed against the $\alpha \beta$ heterodimer of the CD3 epitope, it spares the gamma delta $(\gamma \delta)$ region. These gamma delta $(\gamma \delta)$ T cells have a unique role in the immune response controlling many serious human diseases and perhaps facilitating the development of immunologic tolerance. T10B9 has a relatively short duration of action, depleting $\mathrm{T}$ cells for only 10 to 14 days, unlike the protracted depletion seen with thymoglobulin and Campath-1H. There is no B-lymphocyte depletion with T10B9 as there is with both of the aforementioned reagents. The lack of prolonged lymphocyte depletion may account for less infection observed with T10B9 treatment.
\end{abstract}

Keywords: T10B9.1A-31, $\gamma \delta$ T-cell, monoclonal antibody, Campath-1H, thymoglobulin, OKT3

\section{Introduction}

Induction of immunosuppression has become a standard therapy in the United States with over $70 \%$ of transplantation programs using agents to inhibit the first rejection response. The drugs most often used fall into three categories; 1) the interleukin-2 anti-CD25 selective blocking monoclonal antibodies (mAb) such as basiliximab and daclizumab, 2) polyclonal antisera against T-lymphocytes such as rabbit antilymphocyte globulin (Thymoglobulin) or 3) the mAb alemtuzumab (Campath-1H) which targets $\mathrm{T}$ and $\mathrm{B}$ cells. The latter two agents have significant effects on B-cells. After an initial dose of $30 \mathrm{mg}$, Campath-1H profoundly suppresses T-cells for up to 330 days and B-cells for 90 to 150 days. Thymoglobulin significantly suppresses T-cells for up to 90 days and has a profound anti-B-cell effect from 15 to 980 days, opening many windows for opportunistic infection. (Figure 1). ${ }^{1-11}$ Clearly there would be an advantage for a shorter acting immunosuppression agent which allows T-cell recovery, has little or no effect on B cells and, therefore, does not produce profound long-term immunosuppression. 


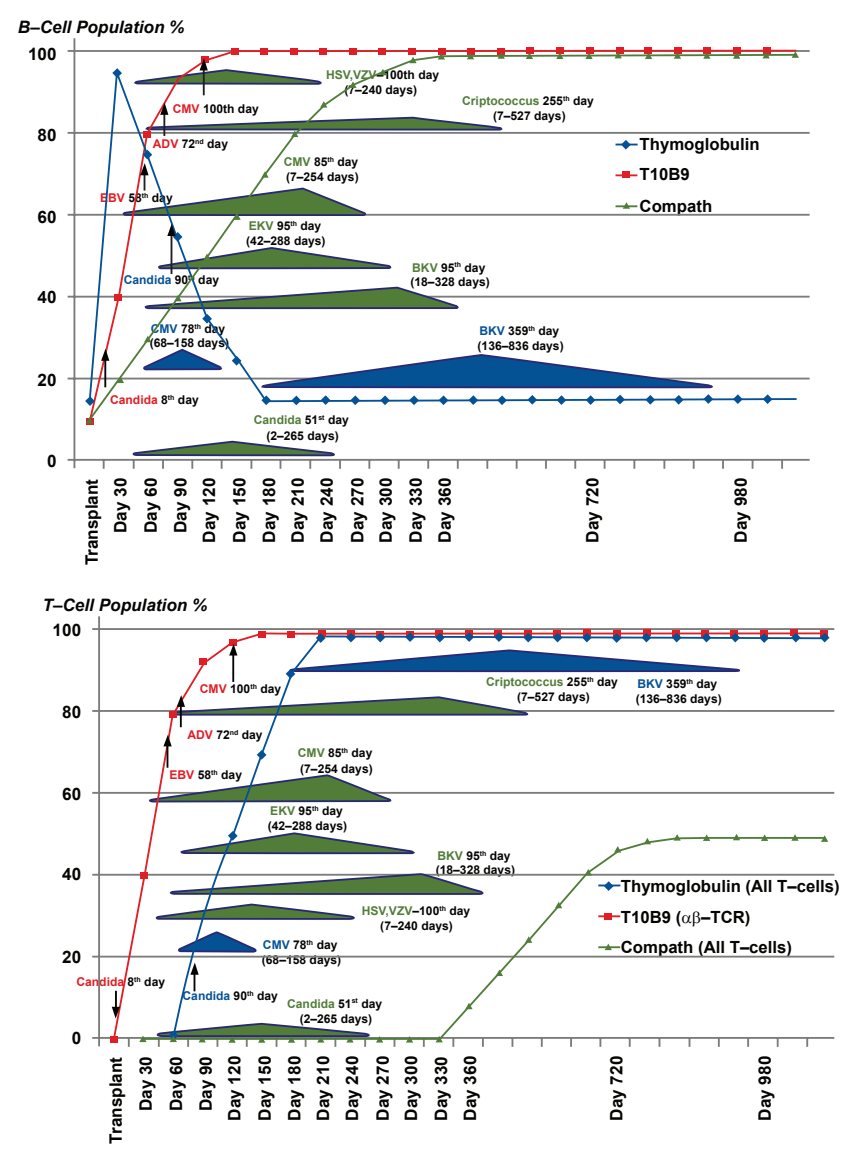

Figure I T and B cell response and peak incidence of opportunistic infections after

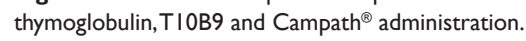

OKT3, the first mAb shown to be effective in treating acute cellular rejection, is such a short-acting agent; however, it causes significant adverse events including those related to its mitogenicity and marked stimulation of inflammatory cytokines. T10B9.1A-31/MEDI-500 is a

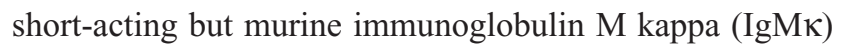
$\mathrm{mAb}$ that is nonmitogenic in vitro which was developed at the University of Kentucky. The purpose of this review is to discuss T10B9.1A-31 (T10B9) briefly describing its manufacturing process, state its known mechanism of action with comparison to OKT3, give a synopsis of T10B9's clinical efficacy, discuss the ability of T10B9 therapy to spare $\gamma \delta \mathrm{T}$ cells which may be important in infection and in the development of tolerance; and finally to support the thesis that a shorter acting more selective anti-T-lymphocyte monoclonal antibody may be a better choice for induction of immunosuppression and/or treatment of acute rejection.

\section{Manufacturing process}

T10B9.1A-31 is a nonmitogenic IgM $\kappa$ isotype murine $\mathrm{mAb}$. It was produced by fusing spleen cells from $\mathrm{BALB} / \mathrm{C}$ mice immunized with human peripheral blood T-lymphocytes with SP2-0/Ag-14 mutant myeloma cells. After preliminary screening and cloning three times by limiting dilution, it was determined that $\mathrm{T} 10 \mathrm{~B} 9$ was directed at a monomorphic antigen expressed on all post-thymic peripheral blood T-cells, but not on other circulating cells or cell precursors. With the help of the College of Pharmacy at the University of Kentucky, the initial production, purification, and lyophilization of stable clinical material was achieved and approved by the US Food and Drug Administration (FDA) for T-cell depletion under BB-IND-4279. Although the first lot of T10B9 was extracted from mouse ascites, subsequent lots were produced in vitro and purified with proprietary multistep ion exchange and molecular sieve chromatography protocols. The final product exhibited $95 \%-100 \%$ protein purity using SDS-PAGE analysis and passed the FDA recommended testing for bacterial, fungal, and viral sterility, general safety and pyrogen. ${ }^{12-14}$

\section{TI0B9: Proposed mechanism of action}

The therapeutic effectiveness of unmodified murine anti- $T$ cell $\mathrm{mAb}$ in reversing acute human allograft rejection is dependent on the combination of both antibody isotype and idiotype interactions with their respective ligands or epitopes. The most successful are those specific for the CD3/TCR $\alpha \beta$ antigen recognition complex. ${ }^{15}$ The mechanism of OKT3 action (a murine $\operatorname{IgG} 2 \mathrm{a} \mathrm{mAb}$ ) includes interaction of its $\mathrm{Fc}$ portion with the high affinity Fc gamma receptor I that is present on monocytes. This produces immune activation followed by immunosuppression. T10B9, a murine IgM $\kappa$ isotype, is specific for the TCR $\alpha \beta$ heterodimer region of the CD3 complex, does not react with Fc gamma receptor I and thus exhibits reduced immune stimulation and the cytokine release syndrome. The TCR $\alpha \beta$ specificity of T10B9 is defined by its ability to modulate the $\alpha \beta$ but not the $\gamma \delta$ TCR whereas OKT3 modulates both types of CD3 T cell receptors. Since T10B9 is directed against the $\alpha \beta$ TCR and OKT3 against the $\mathrm{CD} 3 \varepsilon$ (Epsilon) part of the $\mathrm{CD} 3$ complex, they differ idiotypically. They are isotypically different as well because T10B9 is an IgM $\kappa$ and OKT3 is an IgG2a murine isotype. Therefore, human anti-mouse antibody (HAMA) directed against one monoclonal antibody does not neutralize the other $\mathrm{mAb}$; they are not cross-reactive. Indeed, patients with allograft rejection not responding to therapy with one monoclonal antibody have successfully been treated with the alternative agent. ${ }^{16}$ Attempts to fully humanize T10B9 have been unsuccessful to date; however, there is a chimeric $\mathrm{mAb}$ which appears to be comparable to the parent compound in vitro (JST, personal communication). 


\section{TIOB9 induces short-term lymphocyte depletion}

T10B9 administration results in a rapid decline in lymphoid cell counts with respective epitope modulation and recovery by day 14 . (Figure 2) This is in marked contrast to thymoglobulin and Campath-1H and may be one reason why infections may occur over many months when either of these agents are administered (Figure 1).

\section{TIOB9 does not induce proliferation}

OKT3 is an established potent $\mathrm{T}$ cell mitogen in vivo and in vitro whereas studies suggest that T10B9 reduces proliferation in peripheral blood mononuclear cells (PBMC). In vitro studies were performed to compare the ability of T10B9 and OKT3 to induce proliferation and to determine whether T10B9 in high concentrations or cross-linked on plastic remained incapable of inducing proliferation. The response of PBMC from five normal donors was tested after day 3 of culture. Soluble T10B9 at doses as high as $10 \mathrm{mcg} / \mathrm{mL}$ were non-mitogenic, while soluble OKT3 is a potent mitogen even at low doses. ${ }^{15}$

\section{Cytokine release}

In vitro

In order to compare the ability of both T10B9 and OKT3 to induce cytokine secretion, the in vitro production of cytokines by PBMC from normal donors was determined. OKT3 (20 ng/mL) strongly stimulated tumor necrosis factor- $\alpha$ (TNF $\alpha)$, interferon- $\gamma$ (INF $\gamma$ ), interleukin-2 (IL-2), and IL-6 release whereas T10B9 $(160 \mathrm{ng} / \mathrm{mL})$ failed to induce detectible cytokine release from PBMC over a six-day test period. In a dose escalation study, T10B9 at doses of 80,800 , and $8000 \mathrm{ng} / \mathrm{mL}$ failed to induce TNF $\alpha$ release at 24 hours after exposure. ${ }^{15}$

\section{In vivo}

Plasma samples from kidney transplantation patients rejecting their allograft and undergoing monoclonal MAb antibody therapy were tested for cytokine levels. Samples collected under informed consent two hours following the first dose of either T10B9 or OKT3 underwent ELISA quantitation of TNF $\alpha$, INF $\gamma$, IL-2, and IL-6. Of significance, only six of 30 patients treated with $\mathrm{T} 10 \mathrm{~B} 9$ exhibited a $\mathrm{TNF} \alpha$ response

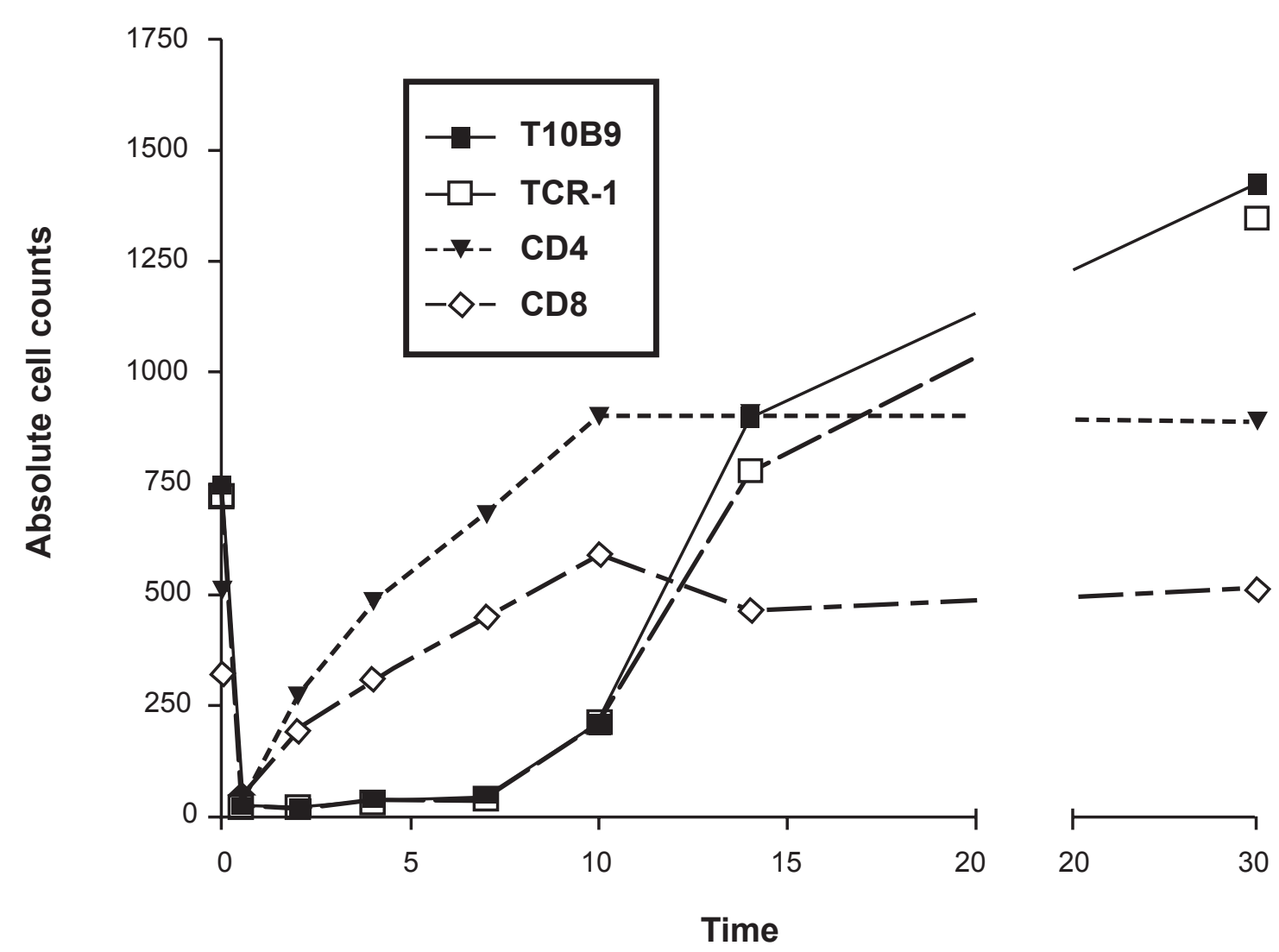

Figure 2 Flow cytometric analysis of lymphoid cells in peripheral blood after administration of TI0B9.IA-3I, OKT3 or TCR-I (anti-T cell receptor $\alpha \beta$ monoclonal antibody $[\mathrm{mAB}])$.There is early T-lymphocyte depletion with re-expression of the CD4 and CD8 epitopes.There is persistent modulation of the CD3/TCR $\alpha \beta$ region in these phenotypically altered $T$ cells for 10 days while the $\mathrm{mABs}$ are being administered with repopulation over $15-40$ days. 
compared to 19 of 23 OKT3-treated patients $(\mathrm{P}=0.001)$. Likewise the T10B9 group exhibited a significantly lower INF $\gamma$ response; however, there was no statistical difference observed in the IL-2 or IL-6 response (Figure 3). ${ }^{15}$

\section{Induction of activation antigens}

Incubation of PBMC with either T10B9 or OKT3 reveals a difference in the in vitro expression of CD69, CD71 (transferrin receptor), CD25 (P55 Il-2 receptor), and DR activation antigens. OKT3 and phytohemagglutinin (PHA) induce expression of all activation antigens tested. None of the PBMC donors tested exhibited CD25 or DR antigen expression following incubation with 10 or $50 \mu \mathrm{g} / \mathrm{mL}$ of T10B9. At $50 \mu \mathrm{g} / \mathrm{mL}$ (molar equivalent of $10 \mathrm{mcg} / \mathrm{mL}$ OKT3) T10B9 did not induce CD69 or CD71 expression. ${ }^{15}$

\section{Induction of apoptosis and IL-2 release in Sup-TI 3 cells}

The ability of OKT3 to induce program cell death (apoptosis) has been well documented. Accordingly, the ability of T10B9 to induce apoptosis in the $\alpha \beta$ T-cell line Sup-T13 after 20 hours of incubation was compared to OKT3 using DNA fragmentation analysis and dexamethasone as the positive control. Both T10B9 and OKT3 induced the DNA fragmentation definitive for apoptosis. The degree of apoptosis was quantitated using flow cytometric methods. The media control exhibited $18 \%$ apoptotic MC540 positive cells. This was increased to $38 \%$ following T10B9 incubation and $43 \%$ with OKT3. The secretion of IL-2 by the Sup-T13 cell line was also determined following T10B9 or OKT3 stimulation. T10B9 proved to be a weaker stimulus for IL-2 than did

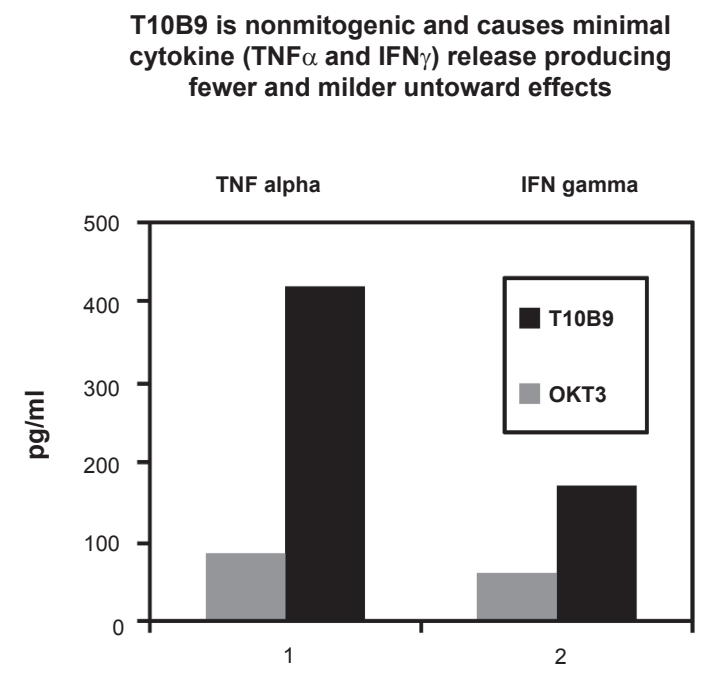

Figure 3 Cytokine release in vivo in patients undergoing treatment for acute cellular rejection with TIOB9 or OKT3.
OKT3. However, T10B9 had the ability to generate a cellular signal as confirmed by the induction of apoptosis and IL-2 release in the human T-cell line Sup-T13. ${ }^{15}$

\section{TIOB9 in clinical solid organ transplantation}

T10B9 has been used successfully to treat acute cellular rejection in renal transplantation. ${ }^{16-18}$ In a phase 2 clinical trial of 81 kidney recipients transplanted at the University of Kentucky, T10B9 provided treatment for biopsy proven acute cellular rejection equal to that of OKT3 with fewer untoward effects, less cytokine release and cytokine nephropathy. Compared to OKT3, serum creatinine began falling after two days of T10B9 therapy instead of three days and the peak serum creatinine rise seen with OKT3 therapy was not present (Figure 4). Consistent with its lack of mitogenicity, there was significantly less cytokine (TNF $\alpha$ and INF $\gamma$ ) release seen after T10B9 administration (Figure 4). Additionally in the T10B9 treated patients there were fewer serious infections, no PTLD and no significant increase in the development of HAMA. ${ }^{18}$

T10B9 has been successfully used as an immunosuppression induction agent in heart transplantation ${ }^{19}$ and in simultaneous kidney-pancreas transplantation..$^{20} \mathrm{~T} 10 \mathrm{~B} 9$ is also used for T-lymphocyte depletion in harvested bone marrow prior to haploidentical bone marrow transplantation to control graft versus host disease. ${ }^{12,13}$ Unlike other monoclonal and polyclonal antibody preparations, there is no experience in treating acute leukemia or aplastic anemia.

\section{TIOB9 specificity for $\alpha \beta$ TCR and for sparing $\gamma \delta$ T-cells}

T10B9 is specific for the T cell $\alpha \beta$ heterodimer region of the CD3 epitope. It modulates the $\alpha \beta$ but not the $\gamma \delta$ TCR whereas OKT3 binds to the $\varepsilon$ (epsilon) portion of the CD3 and modulates the entire epitope. Flow cytometry confirms the absence of $\alpha \beta+\mathrm{T}$ cells after both T10B9 and OKT3 induced modulation; however, after T10B9 administration the $\gamma \delta \mathrm{T}$-cells persist (Figure 5). The sparing of $\gamma \delta \mathrm{T}$ cells was also confirmed in a multicenter bone marrow depletion trial sponsored by the National Heart, Lung and Blood Institute.

\section{Discussion}

Since the onset of human organ transplantation, many new drugs have been added to improve transplantation outcome. In addition to the small molecule shorter acting staples of maintenance immunosuppression that include corticosteroids, calcineurin inhibitors, purine synthesis and mTOR 
inhibitors, biologicals, both monoclonal and polyclonal, have been increasingly used for induction of immunosuppression and treatment of rejection. The addition of these drugs has greatly reduced acute rejection and, in most cases, improved long-term graft survival, albeit there is an increased incidence of cytopenias, renal insufficiency, neurological complications, diabetes, hyperlipidemia, infection complications, and PTLD.

T10B9 is a novel mAb, with a short duration of activity allowing phenotypically altered $\mathrm{T}$ lymphocytes to repopulate after therapy, has no effect on B lymphocytes, is not mitogenic and therefore produces fewer cytokine induced side effects and appears to have less propensity toward infectious complications. One of the unique characteristics of T10B9 is its specificity for only those $\mathrm{T}$ lymphocytes that express the $\alpha \beta$ T-cell receptor (TCR $\alpha \beta)$. Generally $\alpha \beta$ T lymphocytes compose between $95 \%$ and $98 \%$ of all T-cells in the peripheral blood. The remainder are $\mathrm{T}$ lymphocytes that express only the $\gamma \delta$ TCR. In both mice and in humans, $\gamma \delta \mathrm{T}$ lymphocytes are primarily located in proximity to epithelial tissues, including the skin, bowel and lung - all areas of the body that have early contact with the external environment. ${ }^{21,22}$ These $\gamma \delta \mathrm{T}$ cells play a major role in host first-line defense against bacteria, viruses, and fungi. ${ }^{23-29} \mathrm{An}$ important function that differs from the $\alpha \beta \mathrm{T}$ lymphocyte population is the ability of $\gamma \delta \mathrm{T}$ lymphocytes to recognize and respond to such stimuli without the requirement for antigen processing and presentation by accessory cells. In this regard they contribute to innate immunity, ie, the ability to react quickly without requiring prior antigen processing.

Another important feature of their "first-line defense" is well documented in the skin. When skin is injured by any mechanism, a population of $\gamma \delta \mathrm{T}$ lymphocytes called dendritic epidermal T cells (DETC) responds quickly to injury and attach to keratinocytes (the primary cells of the skin). These DETC's secrete pre-growth factors (keratitic growth factors 1 and 2 and insulin growth factor 1) that stimulate regrowth of the epithelium. This phenomenon has been demonstrated in murine lung and is presumed to occur when injury occurs to any epithelial tissue. exposure to mild immune response. This capacity allows $\gamma \delta \mathrm{T}$ lymphocytes to control a variety of infectious agents, such as Nocardia asteroids, Pneumocystis carinii, Mycobacterium bovis, Bordatella pertussis, etc. ${ }^{21,22,30}$ In tissue culture, $\gamma \delta$ T cells killed tumor cells

\section{Mean serum creatinine excluding delayed graft function and crossovers/retreatments}

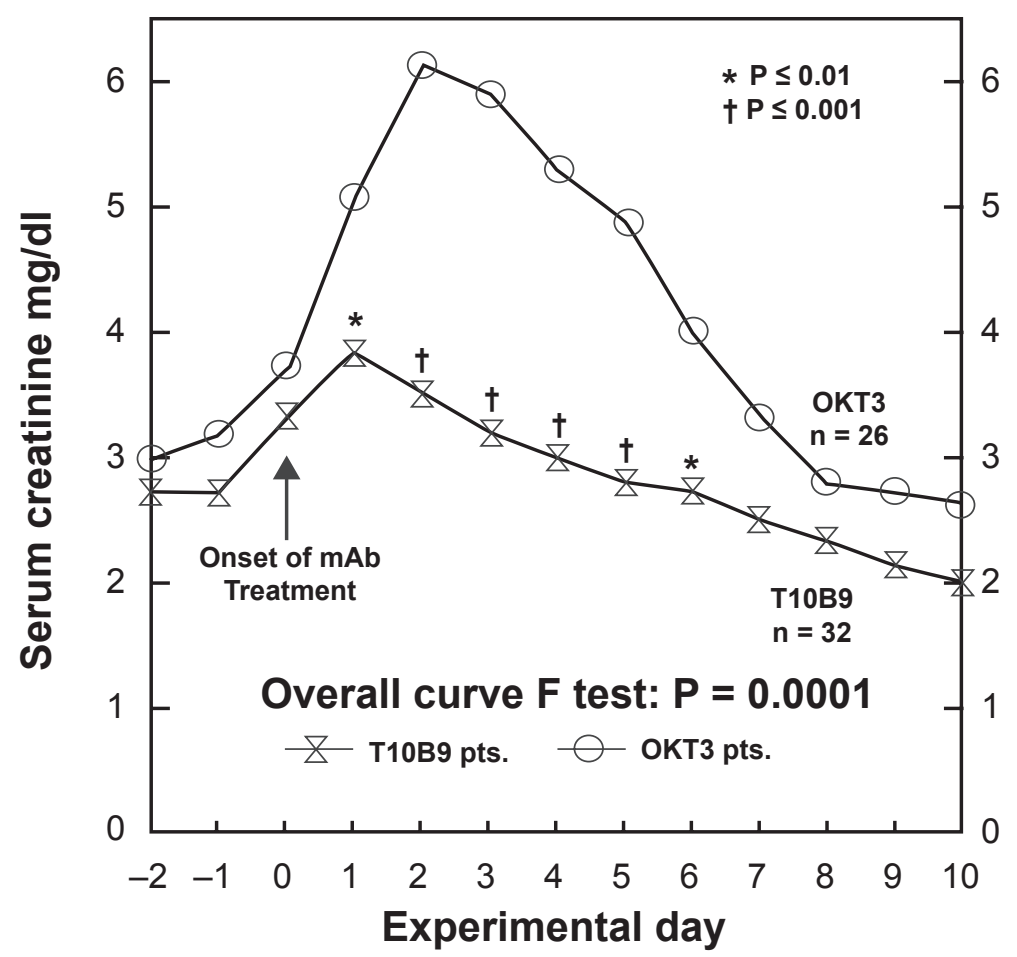

Figure 4 TIOB9 reverses rejection without the cytokine-induced rise in the serum creatinine seen with OKT3. 


\section{T10B9 specifically binds with the $\alpha \beta$ chains and spares the $\gamma \delta$ chains of the T-cell receptor}

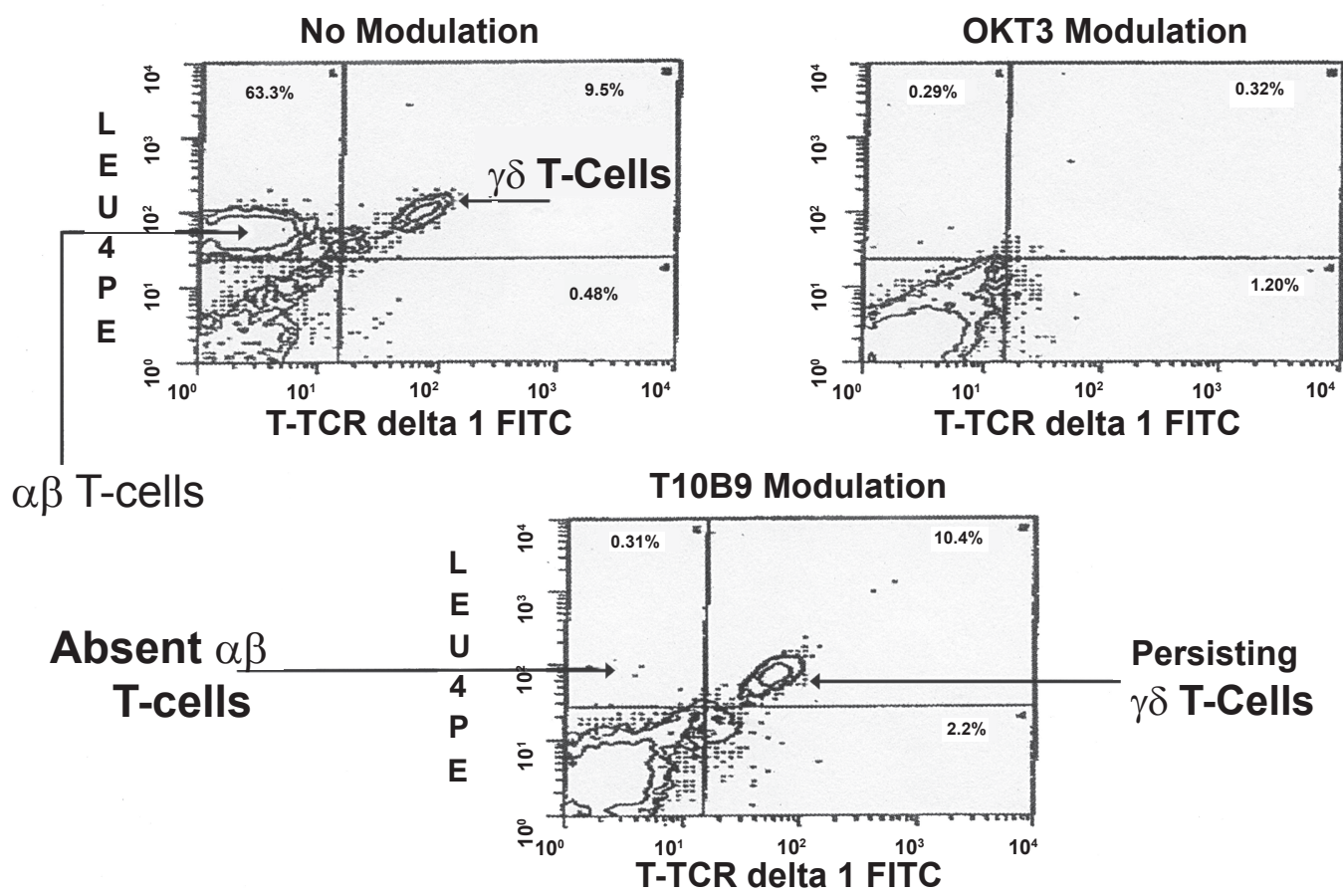

Figure 5 Flow cytometric analysis of peripheral blood T lymphocytes after control (no modulation), OKT3 or TIOB9.TI0B9 modulation shows a persistent population of $\gamma \delta$ T cells and an absence of $\alpha \beta$ T cells whereas both are absent after OKT3 modulation consistent with modulation of the CD3 epitope.

infected with viruses. ${ }^{21,22,24,31} \mathrm{Gamma/delta} \mathrm{T}$ lymphocytes are also able to modulate inflammatory responses in situ, ie, they can directly recognize molecules induced on epithelial cells by stress and respond very rapidly. They can also control the host immune response and thereby present or limit the immunopathology that may occur if there is a sustained response to the initial stress. Taken together it is clear that the $\gamma \delta \mathrm{T}$ lymphocytes are actually a critical component of the immune system with particular reference to the control of many opportunistic infections and the maintenance of homeostasis. Currently, the drugs used for immunosuppression induction or the treatment of rejection suppress both the $\alpha \beta$ and the $\gamma \delta$ $\mathrm{T}$ lymphocytes populations. For example, Thymoglobulin ${ }^{\circledR}$ not only suppresses $\mathrm{T}$ lymphocytes but also B lymphocytes and Campath-1H suppresses T and B lymphocytes and monocytes. There have only been two monoclonal antibodies that uniquely target the $\alpha \beta$ TCR, T10B9 and BMA 031 . These two differ by the fact that BMA 031 is mitogenic and T10B9 is not. Hence, their toxicity profiles are quite different.

Studies have not been performed to demonstrate that sparing $\gamma \delta \mathrm{T}$ lymphocytes makes a difference in solid organ transplantation outcome. Increased $\gamma \delta \mathrm{T}$ cells 100 days post-bone marrow transplantation predict a long-term favorable outcome. However, the direct evidence that sparing $\gamma \delta \mathrm{T}$ lymphocytes is beneficial to transplant outcome is mostly derived from the reported experience using T10B9 for $\mathrm{T}$ cell depletion of donor marrow/stem cells at several centers ${ }^{23,33,34}$ and in solid organ transplantation trials where the overall infection rate was only $16.7 \%{ }^{16,17,19}$ This compares favorably to induction with rabbit anti-thymocyte globulin $\left(\right.$ Thymoglobulin $^{\circledR}$ ) versus basiliximab $\left(\right.$ Simulect ${ }^{\circledR}$ ) where the rate of all infections at 12 months was reportedly $85.8 \%$ and $75.2 \%$, respectively. ${ }^{35}$

The studies above suggest that $\gamma \delta \mathrm{T}$ cells appear to be important in the control of many serious human diseases, most of which unfortunately accompany immunosuppression. These cells also appear to have the capability to facilitate the development of immunologic tolerance. These are features that could be maximized by using T10B9 for both transplant immunosuppression induction and for treatment of rejection. Parenthetically, T10B9 may be particularly useful in composite tissue transplantation. This hypothesis is based on the observation of Siemionow and others ${ }^{36-38}$ that an antirat Mab directed only at the $\mathrm{a} / \mathrm{b}$ chains of the $\mathrm{T}$-cell receptor 
was critically important for the development of long term tolerance to allogeneic composite transplants. Thus, sparing $\gamma \delta \mathrm{T}$ lymphocytes may provide an important benefit in stem cell and solid organ transplantation.

In summary, T10B9 (MEDI-500) is a murine IgMא anti-human $\mathrm{T}$ cell monoclonal antibody with reduced immune activation potential both in vitro and in vivo. In vitro it does not induce DNA synthesis, the expression of activation antigens or cytokine release, which is in contrast to OKT3. Clinically T10B9 is effective in the reversal of acute renal allograft rejection, exhibits lower morbidity and induces lower TNF $\alpha$ and INF $\gamma$ levels after infusion. Finally, it spares $\gamma \delta \mathrm{T}$ lymphocytes which have a unique and important role in the immune response; ie, in controlling many serious human diseases while inducing $\alpha \beta$ T cell immunosuppression and perhaps facilitating the development of immunologic tolerance. Given the apparent advantages of T10B9 over currently available polyclonal and monoclonal reagents, would a shorter acting immunosuppressive agent be a better therapeutic choice? Is it time for a paradigm shift?

\section{Disclosure}

The authors report no conflicts of interest in this work.

\section{References}

1. Peleg AY, Husain S, Kwak EJ, et al. Opportunistic infections in 547 organ transplant recipients receiving alemtuzumab, a humanized monoclonal CD-52 antibody. Clin Infect Dis. 2007;44(2):204-212.

2. Alinari L, Lapalombella R, Andritsos L, Baiocchi RA, Lin TS, Byrd JC. Alemtuzumab (Campath-1H) in the treatment of chronic lymphocytic leukemia. Oncogene. 2007;26(25):3644-2653.

3. Chakrabarti S, Osman H, Collingham K, Milligan DW. Polyoma viruria following $\mathrm{T}$-cell-depleted allogeneic transplants using Campath-1H: incidence and outcome in relation to graft manipulation, donor type and conditioning. Bone Marrow Transplant. 2003;31(5):379-386.

4. De Santo LS, Romano G, Mastroianni C, et al. Role of immunosuppressive regimen on the incidence and characteristics of cytomegalovirus infection in heart transplantation: a single-center experience with preemptive therapy. Transplant Proc. 2005;37(6):2684-2687.

5. Sepulveda L. Llancaqueo M, Zamorano J, Bermudez C, Cortes C. Cytomegalovirus infections in cardiac transplant patients: 5 and experience at a clinical hospital, university of Chile. Transplant Proc. 2007;39(3):622-624.

6. Nash RA, Dansey R, Storek J, et al. Epstein-Barr virus-associated posttransplantation lymphoproliferatvie disorder after highdose immunosuppressive therapy and autologous CD34-selected hematopoietic stem cell transplantation for severe autoimmune diseases. Biol Blood Marrow Transplant. 2003;9(9):583-591.

7. Lipshutz GS, Mahanty H, Feng S, et al. Polyomavirus-associated nephropathy in simultaneous kidney-pancreas transplant recipients: a single-center experience. Transplant Proc. 2004;36(4):1097-1098.

8. Duclos AJ, Krishnamurthi V, Lard M, et al. Prevalence and clinical course of BK virus nephropathy in pancreas after kidney transplant patients. Transplant Proc. 2006;38(10):3666-3672.

9. Casper J, Camitta B, Truitt R, et al. Unrelated bone marrow donor transplants for children with leukemia or myelodysplasia. Blood. 1995;85(9):2354-2363.
10. Bunin $\mathrm{N}$, Aplenc R, Iannone R, et al. Unrelated donor bone marrow transplantation for children with severe aplastic anemia: minimal GVHD and durable engraftment with partial T cell depletion. Bone Marrow Transplant. 2005;35(4):369-373.

11. Thompson JS, Pomeroy C, Kryscio RJ, et al. Use of a T cell-specific monoclonal antibody, T10B9, in a novel allogeneic stem cell transplantation protocol for hematologic malignancy high-risk patients. Biol Blood Marrow Transplant. 2004;10(12):858-866.

12. Hensley-Downey PJ, Parrish RS, McDonald JS, et al. Combined in vitro and in vivo $\mathrm{T}$ lymphocyte depletion for the control of graft-versus-host diseases following haploidentical marrow transplant.Transplantation. 1996;61(5):735-745.

13. Fleming DR, Hensley-Downey PJ, Romond EH, et al. Allogeneic bone marrow transplantation with T-cell depleted partially matched related donors for advanced acute lymphoblastic leukemia in children and Adults: A comparative matched cohort study. Bone Marrow Transplant. 1996;17(6):917-922.

14. Waid TH, Lucas BA, Amlot P, et al. T10B9.1A-31 anti-T-cell monoclonal antibody: preclinical studies and clinical treatment of solid organ allograft rejection. Am J Kidney Dis. 1989;14(5 Suppl 2):61-70.

15. Brown SA, Lucas BA, Waid TH, McKeown JW, Barve S, Jackson LR, Thompson JS. T10B9 (MEDI-500) mediated immunosuppression: studies on the mechanism of action. Clin Transplant. 1996;10(6 part 2):607-613.

16. Waid TH, Lucas BA, Thompson JS, et al. Treatment of acute cellular rejection with T10B9.1A-31 or OKT3 in renal allograft recipients. Transplantation. 1992;53(1):80-86.

17. Waid TH, Lucas BA, Thompson JS, et al. Treatment of acute cellular kidney allograft rejection with T10B9.1A-31 anti-T-cell monoclonal antibody. Transplant Proc. 1989;21(1 PT 2):1778-1784.

18. Waid TH, Lucas BA, Thompson JS, et al. Treatment of renal allograft rejection with T10B9.1A-31 or OKT3: Final analysis of a phase 2 clinical trial. Transplantation. 1997;64(2):274-281.

19. Waid TH, Thompson JS, McKeown JW, Brown SA, Sekela ME. Induction immunotherapy in heart transplantation with T10B9.1A-31: A phase 1 study. J Heart Lung Transplant. 1997:16(9):913-916.

20. Reddy KS, Ranjan D, Johnston TD, et al. Pancreas transplantation, current status and experience at the University of Kentucky. J Ky Medication Assn. 2002;100:278-284.

21. Thedrez A, Sabourin C, Gertner J, et al. Self/non-self discrimination by human gamma/delta T-cells: simple solutions for a complex issue question. Immunological Rev. 2007;215:123-135.

22. Jameson J, Havran WL. Skin gamma/delta T-cell functions in homeostasis and wound healing. Immunological Rev. 2007;215:114-122.

23. Lamb LS, Lopez RV. $\gamma \delta$ T-Cells: A New Frontier for Immunotherapy? Biol Blood Marrow Transplant. 2005;11:161-168.

24. D’Offizi G, Giola C, Martini F, et al. Gamma/delta T-cells and resolution of cytomegalovirus infection in HIV/HCV co-infected patients after liver transplantation. Transplantation. 2005;80:1523-1524.

25. Ponomarev ED, Dittel BN. Gamma/delta T-cells regulate the extent and duration of inflammation in the central nervous system by a Fas ligand-dependent mechanism. J Immunol. 2005;174:4678-4687.

26. Poccia F, Agrati C, Castilletti C, et al. Anti-severe acute respiratory syndrome coronavirus immune responses: the role played by $\mathrm{V}$ gamma 9 V delta 2 T cells. J Infect Dis. 2006;193:1244-1249.

27. Agrati C, Castilletti C, Santis R, et al. Interferon-gamma-mediated antiviral immunity against orthopoxvirus is provided by gamma/delta T-cells. J Infect Dis. 2006;193:1606-1607.

28. Wang T, Gao Y, Scully E, et al. Gamma delta T cells facilitate adaptive immunity against West Nile virus infection in mice. J Immunol. 2006;177(3):1825-1832.

29. Lockard E, Green AM, Flynn JL. IL-17 production is dominated by gammadelta T-cells rather than CD4 T-cells during Mycobacterium tuberculosis infection. J Immunol. 2006;177:4662-4669.

30. Van-der-Heyde HC, Batcheider JM, Sandor M, Weidanz WP. Splenic gammadelta T-cells regulated by CD4+ T-cells are required to control chronic plasmodium chabaudi malaria in the V-cell-deficient mouse. IMF Immun. 2006;74:2717-2715. 
31. Manno N, Shiohara T, Yamamoto TH, et al. Gamma/delta $\gamma \delta$ T-cells; firefighters or fire boosters in the front lines of inflammatory responses. Immunological Rev. 2007;215:103-113.

32. Koshiba T, Li Y, Takemura M, et al. Clinical, immunological, and pathological aspects of operational tolerance after pediatric living-donor liver transplantation. Transplant Immunol. 2007;17:94-97.

33. Vodanovic-Jankovic S, Vrobyski WR. Gamma/delta T-cells do not require fully functional cytotoxic pathways or the ability to recognize recipient alloantigens to prevent graft rejection. Biol Blood Marrow Transplant. 2006;12:1125-1134.

34. Godder KT, Henslee-Downey PJ, Mehta J, et al. Long term disease-free survival in acute leukemia patients recovering with increased $\gamma \delta \mathrm{T}$-cells after partially mismatched related donor bone marrow transplantation." Bone Marrow Transplantation. 2007;39:751-757.
35. Brennan D, et al. Rabbit antithymocyte globulin versus basiliximab in renal transplantation. $N$ Engl J Med. 2006;355(19):1967-1977.

36. Scharpf J, Strome M, Siemionow M. Immunomodulation with anti-alphabeta $\mathrm{T}$-cell receptor monoclonal antibodies in combination with cyclosporine A improves regeneration in nerve allografts. Microsurgery. 2006;26:599-607.

37. Nomoto K, Yung-Yu K, Omoto K, et al. Tolerance induction in a fully allogeneic combination using anti-T cell receptor- $\alpha \beta$ monoclonal antibody, low dose irradiation, and donor bone marrow transfusion. Transplantation. 1995;59:395-401.

38. Ozer K, Oke R, Gurunluoglu R. Induction of tolerance to hind limb allografts in rats receiving cyclosporine $\mathrm{A}$ and antilymphocyte serum: effect of duration of the treatment. Transplantation $2003 ; 75: 31-36$

\section{Publish your work in this journal}

Drug Design, Development and Therapy is an international, peerreviewed open-access journal that spans the spectrum of drug design and development through to clinical applications. Clinical outcomes, patient safety, and programs for the development and effective, safe, and sustained use of medicines are a feature of the journal, which has also been accepted for indexing on PubMed Central. The manuscript management system is completely online and includes a very quick and fair peer-review system, which is all easy to use. Visit http://www.dovepress.com/testimonials.php to read real quotes from published authors.

Submit your manuscript here: http://www.dovepress.com/drug-design-development-and-therapy-journal 